\title{
Enhanced Inhibition of a Mutant Neuronal Nicotinic Acetylcholine Receptor by Agonists: Protection of Function by (E)-N-Methyl-4-(3-pyridinyl)-3-butene-1-amine (TC-2403)
}

\author{
ROGER L. PAPKE \\ Department of Pharmacology and Therapeutics, University of Florida, Gainesville, Florida \\ Received October 16, 2001; accepted November 26, $2001 \quad$ This article is available online at http://jpet.aspetjournals.org
}

\begin{abstract}
Inhibition of neuronal nicotinic receptors can be regulated by sequence in the $\beta$ subunit second transmembrane domain (TM2). The incorporation of a $\beta 4\left(6^{\prime} \mathrm{F} 10^{\prime} \mathrm{T}\right)$ subunit, which contains sequence from the muscle $\beta$ subunit at the TM2 6' and 10' positions of the neuronal $\beta 4$ subunit, increases the loss of receptor responsiveness after the application of acetylcholine (ACh), nicotine, or 3-(2,4-dimethoxybenzylidene)-anabaseine (DMXB), an $\alpha 7$-selective partial agonist. Inhibition of receptor responsiveness following agonist exposure may occur through either an enhancement of desensitization, increased channel block by an agonist, or alternatively via allosteric modulation. Although DMXB produces very little activation of either $\alpha 3 \beta 4$ or $\alpha 3 \beta 4\left(6^{\prime} \mathrm{F} 10^{\prime} \mathrm{T}\right)$ receptors, DMXB shows an enhanced use-and voltage-dependent inhibition of $\alpha 3 \beta 4\left(6^{\prime} \mathrm{F} 10^{\prime} \mathrm{T}\right)$ receptors compared with wild-type. In contrast, the $\alpha 4 \beta 2$-selective agonist
\end{abstract}

(E)-N-methyl-4-(3-pyridinyl)-3-butene-1-amine (TC-2403, previously identified as RJR-2403) shows increased activation of $\alpha 3 \beta 4\left(6^{\prime} \mathrm{F} 10^{\prime} \mathrm{T}\right)$ receptors compared with $\alpha 3 \beta 4$ receptors (as related to ACh activation) but with no significant increase in antagonist activity. The interaction between the binding of local anesthetics and the functional inhibition produced by these agonists was evaluated. The binding of the local anesthetics to their inhibitory sites does not affect inhibitory effects of DMXB and nicotine. However, TC-2403 can protect receptor function from the inhibitory effects of other agonists, suggesting that TC-2403, as well as agonists that cause inhibition, may be binding to an allosteric site, either promoting or inhibiting channel opening. The ability of TC-2403 to protect receptor function from agonist-induced inhibition may point toward valuable new combination drug therapies.
Our current understanding of the function of the ligandgated ion channels that mediate synaptic function is founded on early studies of the nicotinic receptor of the neuromuscular junction. However, the analysis of nicotinic acetylcholine receptor function is complicated by the fact that, in addition to activating receptors, exposure to agonists ultimately decreases receptor responsiveness. The classical concept of desensitization, originally put forth by Katz and Thesleff (1957), is that it represents conversion of the receptor to an alternative nonfunctional conformational state and that this conversion is promoted by the binding of agonist to the same sites that produce channel activation.

Although it is clear that after an episode of strong activation, receptor responsiveness will decline in the continued presence of an agonist, producing a decrease in function that can persist after the agonist is removed, it is difficult to distinguish classical (i.e., Katz and Thesleff)

Studies were supported by the University of Florida College of Medicine Incentive award and by National Institutes of Health Grant NS32888-02. desensitization from other processes, such as channel block by agonist or allosteric modulation, which might also lead to a decrease in receptor responsiveness. Moreover, the degree to which receptor responsiveness is decreased subsequent to agonist-evoked activation varies, depending on the specific agonist used and the receptor subtype under investigation. For example, nicotine is thought to produce more "desensitization" than ACh, and brain-type receptors (i.e., receptors composed of $\alpha 4$ and $\beta 2$ subunits) are more sensitive to this effect of nicotine than are receptors composed of the ganglionic subunits, $\alpha 3$ and $\beta 4$ (Papke et al., 2000).

If a strict definition of desensitization is adopted as being a conformational change consequent to the binding of an agonist at the same sites that promote activation, then the challenge exists to distinguish desensitization from the other effects of agonists that decrease receptor function by binding to sites other than the activation sites. For example, some agonists have been shown to produce voltage-dependent open-channel block. Although the decrease in receptor func-

ABBREVIATIONS: ACh, acetylcholine; AChR, ACh receptor; TM2, second transmembrane domain; TC-2403, (E)- $N$-methyl-4-(3-pyridinyl)-3butene-1-amine; DMXB, 3-(2,4-dimethoxybenzylidene)-anabaseine; QX-314, 2-(triethylamino)- $N$-(2,6-dimethylphenyl)-acetamide; tetracaine, $N, N$ dimethylaminoethyl-4-butylaminobenzoate. 
tion resulting from open-channel block by an agonist should not be attributed to desensitization, this distinction is confounded by the fact that open-channel blockers may also promote classical desensitization by increasing the time that agonist will remain bound to the activation sites (Neher and Steinbach, 1978). Likewise, the binding of agonists and other modulatory substances to allosteric sites has been suggested to enhance the classical desensitization produced by the binding of an agonist to the activation sites (Galzi et al., 1991). Because of these confounding issues, it is nearly impossible to identify a decrease in receptor function as strictly due to desensitization. Therefore, this paper will refer to any form of decreased receptor responsiveness observed after activation by an agonist as "agonist-induced residual inhibition", using this term without prejudice to refer to what might be desensitization or alternatively a decrease in subsequent evoked responses due to the effect of an agonist binding at sites other than those that promote activation. However, through competition experiments and evaluation of the use and voltage dependence of the agonist-induced inhibition, it may ultimately be possible to clarify the mechanisms of inhibition.

A chimeric form of the $\alpha 3 \beta 4$ neuronal nicotinic receptor previously described (Webster et al., 1999) showed an enhancement in the agonist-induced residual inhibition produced by exposure to nicotine and acetylcholine. Site-directed mutations in the $\beta 4$ subunit showed that two residues in the pore-forming TM2 were responsible for this effect (Webster et al., 1999). Specifically, $\beta 4\left(6^{\prime} \mathrm{F} 10^{\prime} \mathrm{T}\right)$ subunits, which contain substitutions of corresponding residues from the muscle-type $\beta 1$ subunit at the $6^{\prime}$ and $10^{\prime}$ positions of the neuronal $\beta 4$ subunit gating domain, showed greatly increased agonistinduced residual inhibition by $\mathrm{ACh}$ and nicotine compared with wild-type receptors.

In this paper, the nicotine-mediated inhibition of $\alpha 3 \beta 4$ $\left(6^{\prime} \mathrm{F} 10^{\prime} \mathrm{T}\right)$ receptors is examined in detail to determine whether this form of agonist-induced residual inhibition has properties that would be consistent with the traditional concept of desensitization or alternatively might represent other forms of receptor inhibition. Two subtype-selective drugs were used to study the mutant receptors, TC-2403 (metanicotine, previously identified as RJR-2403) and DMXB (also known as GTS-21). TC2403 , which is a full agonist of $\alpha 4 \beta 2$ receptors, has less than $20 \%$ efficacy on wild-type $\alpha 3 \beta 4$ receptors (Papke et al., 2000). DMXB, which activates $\alpha 7$ about $30 \%$ as effectively as $\mathrm{ACh}$, has very low efficacy (less than $2 \%$ ) on wild-type $\alpha 3 \beta 4$ receptors. Interestingly, whereas DMXB produces virtually no activation of wild-type $\alpha 3 \beta 4$ receptors, it can produce an inhibition of the responses to full agonists (Meyer et al., 1997, 1998). In contrast, the more effective partial agonist TC-2403 produces little or no agonist-induced residual inhibition and does not affect the responses to other agonists (Papke et al., 2000). These drugs were therefore used to determine whether they might in fact discriminate between the activation and inhibitory effects of agonists.

Our data indicate that at least some aspects of the agonistinduced residual inhibition of wild-type and mutant receptors by DMXB and nicotine are inconsistent with the traditional concept of desensitization and may represent other forms of inhibition such as channel block or allosteric modulation.

\section{Materials and Methods}

cDNA Clones. Rat cDNA clones for the neuronal receptors (Heinemann et al., 1986) were used. The sequences of the TM2s of the relevant subunits are shown below. Adopting the terminology proposed by Miller (1988), the 20 residues in the proposed second transmembrane sequence are identified as $1^{\prime}$ through $20^{\prime}$.

\begin{tabular}{|c|c|}
\hline$\alpha 3$ & VTLCISVLLSLTVFLLVITETIPST \\
\hline$\beta 4$ & MTLCISVLLALTFFLLLISKIVPPT \\
\hline$\beta 1$ & MGLS IFALLTLTVFLLLLADKVPET \\
\hline & $\begin{array}{llll}1^{\prime} & 6^{\prime} & 10^{\prime} & 20^{\prime}\end{array}$ \\
\hline
\end{tabular}

Construction of Site-Directed Mutants. Site-directed mutagenesis was conducted with QuickChange kits (Stratagene, La Jolla, CA). In brief, two complimentary oligonucleotides that contain the desired mutation flanked by 10 to 15 bases of unmodified nucleotide sequence were synthesized. Using a thermal cycler, Pfu DNA polymerase extended the sequence around the whole vector, generating a plasmid with staggered nicks. Each cycle built only off the parent strands; therefore, there was no amplification of misincorporations. After 12 to 16 cycles, the product was treated with DpnI, which digested the methylated parent DNA into numerous small pieces. The product was then transformed into Escherichia coli cells, which repaired the nicks. Mutations were confirmed by DNA sequencing.

Preparation of RNA. After linearization and purification of cloned cDNAs, RNA transcripts were prepared in vitro using the appropriate mMessage mMachine kit from Ambion Inc. (Austin, TX).

Expression in Xenopus Oocytes. Mature $(>9 \mathrm{~cm})$ female Xenopus laevis African toads (Nasco, Ft. Atkinson, WI) were used as a source of oocytes. Prior to surgery, frogs were anesthetized by placing the animal in a $1.5 \mathrm{~g} / \mathrm{l}$ solution of MS222 (3-aminobenzoic acid ethyl ester). Eggs were removed from an incision made in the abdomen.

To remove the follicular cell layer, harvested oocytes were treated with collagenase $(1.25 \mathrm{mg} / \mathrm{ml})$ from Worthington Biochemical Corporation (Freehold, $\mathrm{NJ}$ ) for $2 \mathrm{~h}$ at room temperature in calcium-free Barth's solution (88 mM NaCl, $10 \mathrm{mM}$ HEPES, pH 7.6, $0.33 \mathrm{mM}$ $\mathrm{MgSO}_{4}, 0.1 \mathrm{mg} / \mathrm{ml}$ gentamicin sulfate). Subsequently, stage 5 oocytes were isolated and injected with $50 \mathrm{nl}(5-20 \mathrm{ng})$ each of a mixture of the appropriate subunit cRNAs following harvest. Recordings were made 1 to 7 days after injection, depending on the cRNAs being tested.

Chemicals. DMXB (GTS-21) was supplied by Taiho Pharmaceuticals (Tokyo, Japan). QX-314, tetracaine, (-)-nicotine, and all other chemicals for electrophysiology were obtained from Sigma-Aldrich (St. Louis, MO). Fresh acetylcholine stock solutions were made daily in Ringer's solution and diluted.

Electrophysiology. Oocyte recordings were made with a Warner Instruments (Hamden, CT) OC-725C oocyte amplifier and RC-8 recording chamber interfaced to either a Macintosh (Apple, Cupertino, CA) or Gateway (San Diego, CA) personal computer. Data were acquired using Labview software (National Instruments, Austin, TX) or pClamp8 (Axon Instruments, Union City, CA) and filtered at a rate of $6 \mathrm{~Hz}$. Oocytes were placed in a Warner recording chamber with a total volume of about $0.6 \mathrm{ml}$ and perfused at room temperature with frog Ringer's solution ( $115 \mathrm{mM} \mathrm{NaCl}, 2.5 \mathrm{mM} \mathrm{KCl}, 10 \mathrm{mM}$ HEPES, pH 7.3, $1.8 \mathrm{mM} \mathrm{CaCl}_{2}$ ) containing $1 \mu \mathrm{M}$ atropine to inhibit potential muscarinic responses. A Mariotte flask filled with Ringer's solution was used to maintain a constant hydrostatic pressure for drug deliveries and washes. Drugs were diluted in perfusion solution and loaded into a 2-ml loop at the terminus of the perfusion line. A bypass of the drug-loading loop allowed bath solution to flow continuously while the drug loop was loaded, and then drug application was synchronized with data acquisition by using a two-way electronic valve. The rate of bath solution exchange and all drug applications was $6 \mathrm{ml} / \mathrm{min}$. Current electrodes were filled with a solution containing $250 \mathrm{mM} \mathrm{CsCl}, 250 \mathrm{mM} \mathrm{CsF}$, and $100 \mathrm{mM}$ EGTA and had 
resistances of 0.5 to $2 \mathrm{M} \Omega$. Voltage electrodes were filled with $3 \mathrm{M}$ $\mathrm{KCl}$ and had resistances of 1 to $3 \mathrm{M} \Omega$.

Experimental Protocols and Data Analysis. Current responses to drug application were studied under a two-electrode voltage clamp at a holding potential of $-50 \mathrm{mV}$ unless otherwise noted. Holding currents immediately prior to agonist application were subtracted from measurements of the peak response to an agonist. All $\mathrm{ACh}$ and other drug applications were separated by wash periods of 5 min unless otherwise noted. At the start of recording, all oocytes received two initial control applications of $100 \mu \mathrm{M}$ ACh. Although there was frequently a rundown between the first and second responses to $100 \mu \mathrm{M} \mathrm{ACh}$, it was determined in a series of control experiments that for both the wild-type and mutant receptors, ACh responses were essentially stable after the second $100 \mu \mathrm{M}$ ACh application (see Fig. 1). Once ACh responses stabilized, responses to experimental drug applications were obtained in alternation with further $100 \mu \mathrm{M}$ control ACh applications. To correct for the variability in the level of channel expression in each oocyte, all drug application responses were normalized to the respective $\mathrm{ACh}$ control response obtained $5 \mathrm{~min}$ before the experimental drug application. Typically, different lots of oocytes and different injection sets varied

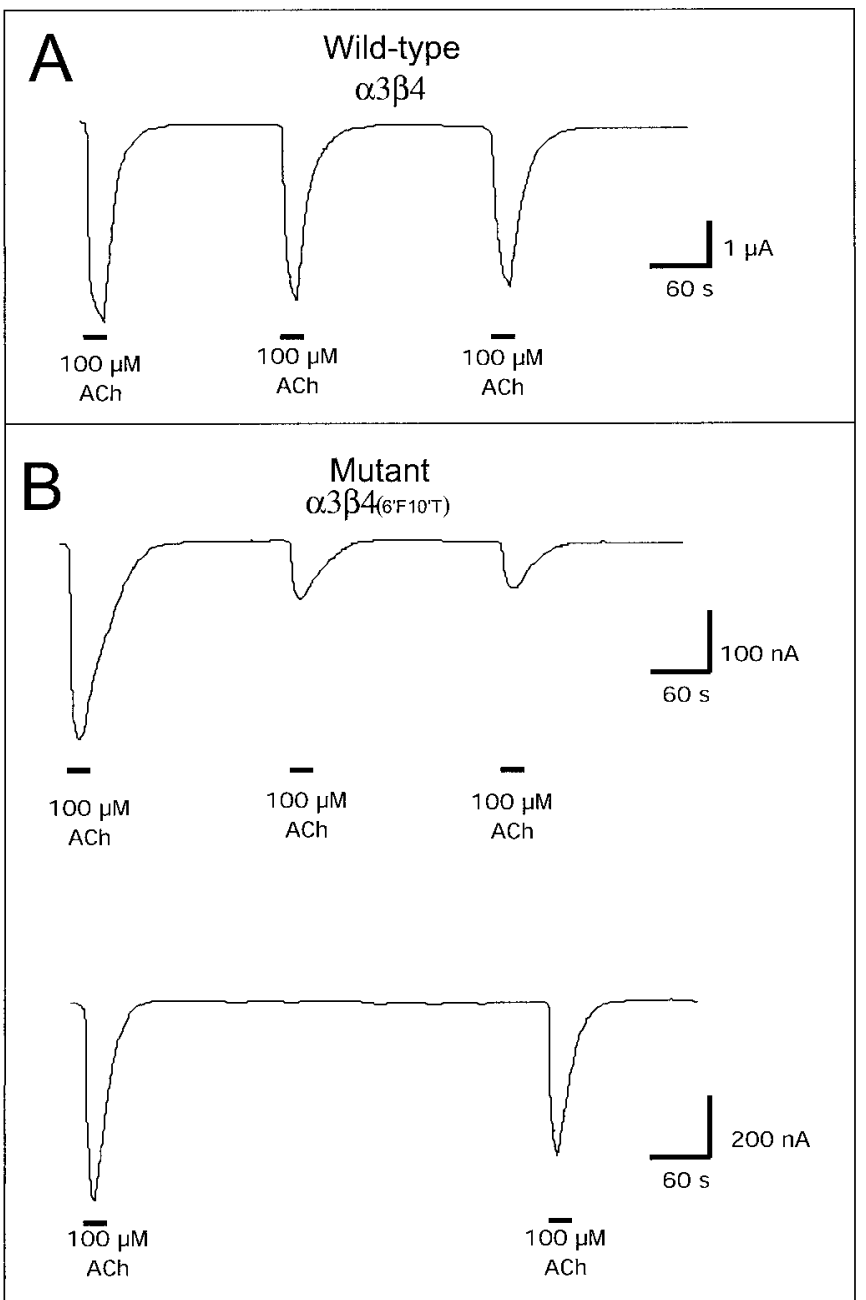

Fig. 1. Effects of $\beta 4$ TM2 $6^{\prime} / 10^{\prime}$ mutations $\left[\beta 4\left(6^{\prime} \mathrm{F} 10^{\prime} \mathrm{T}\right)\right]$ on control ACh responses. A, control ACh responses from an oocyte expressing wild-type $\alpha 3 \beta 4$ receptors showing the stability of the responses recorded at 5 -min intervals. B, responses of oocytes expressing $\alpha 3 \beta 4\left(6^{\prime} \mathrm{F} 10^{\prime} \mathrm{T}\right)$ receptors. As shown in the top trace, when ACh is applied at 5-min intervals there is a significant drop in the second response, and then control ACh responses remain relatively stable. The bottom trace shows that control ACh responses show essentially full recovery between the first and second applications with a 10 -min wash period. in the magnitude of their current responses at any fixed time after injections were made. However, there were no systematic difference between the wild-type mutant receptors in this study. By recording either sooner or later after the time of injection, cells were used when expression was in an optimal range of 500 to $3000 \mathrm{nA}$. Due to our normalization procedure, the absolute magnitude of the responses (within the 500-3000 nA range) does not impact the experimental measurements.

To measure residual inhibitory effects of experimental drug applications and otherwise confirm the continued stability of the ACh control responses in a given cell, comparisons were made between the responses to $100 \mu \mathrm{M}$ ACh obtained 5 min before an experimental drug application (C1) and the $100 \mu \mathrm{M}$ ACh response obtained after a further 5-min wash $(\mathrm{C} 2)$. The ratio of $\mathrm{C} 2 / \mathrm{C} 1$ is referred to as the recovery response (Fig. 2B; Fig. 3, B and D). Measurements of C2/C1 that were $<0.75$ were taken to indicate that the experimental drug application produced some form of residual inhibition. An oocyte was not used for further experimental drug applications when the measurements of $\mathrm{C} 2 / \mathrm{C} 1$ became less than 0.75 .
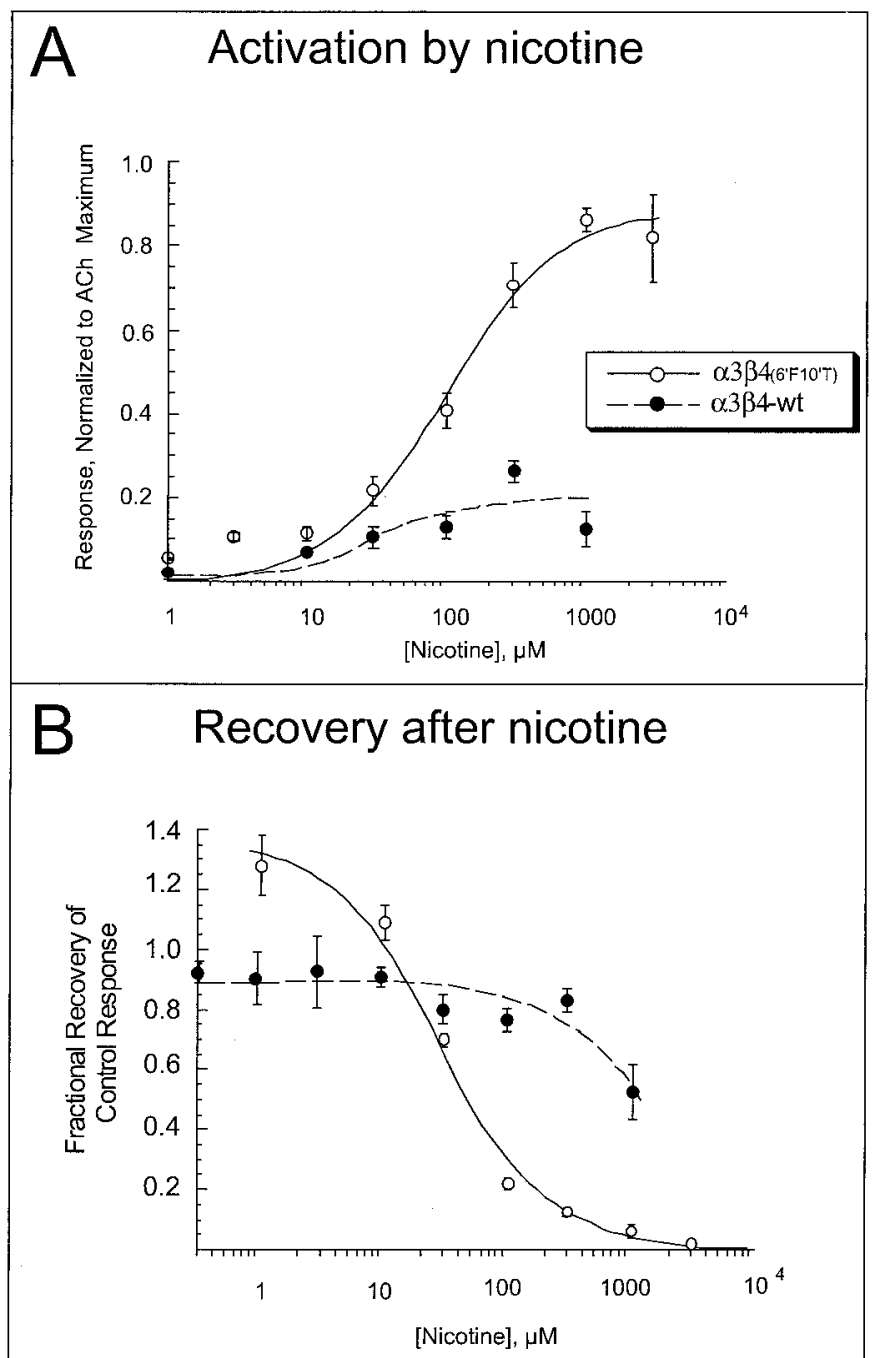

Fig. 2. Concentration-response curves for the effect of nicotine on $\alpha 3 \beta 4$ and $\alpha 3 \beta 4\left(6^{\prime} \mathrm{F} 10^{\prime} \mathrm{T}\right)$ receptors. A, the concentration-response relationship for the activation of the peak currents by nicotine. Data are expressed relative to ACh maximum responses (see Materials and Methods). B, the concentration-response relationship for the recovery of control ACh response amplitude measured $5 \mathrm{~min}$ after nicotine was applied at the indicated concentrations. Each point represents the average normalized response of at least four cells. 
Means and standard errors (S.E.M.) were calculated from the normalized responses of at least four oocytes for each experimental concentration. For concentration-response relations (Figs. 2 and 3), data were plotted using Kaleidagraph 3.0.2 (Abelbeck/Synergy Software, Reading, PA), and curves were generated from the Hill equation.

$$
\text { Response }=\frac{I_{\max }[\text { agonist }]^{n}}{[\text { agonist }]^{n}+\left(\mathrm{EC}_{50}\right)^{n}}
$$

where $I_{\max }$ denotes the maximal response for a particular agonist/ subunit combination, and $n$ represents the Hill coefficient. $I_{\max }, n$, and $\mathrm{EC}_{50}$ were all unconstrained for the fitting procedures. To show the relative efficacy of each experimental agonist compared with $\mathrm{ACh}$, for all the concentration response curves, the data were initially normalized to the $100 \mu \mathrm{M}$ ACh responses obtained in the same cells and then scaled by the ratio of $100 \mu \mathrm{M}$ ACh control responses to the maximal $\mathrm{ACh}$ responses determined in separate experiments (not shown). For both the wild-type and mutant receptors, maximal responses to ACh were obtained with $1 \mathrm{mM}$ ACh. The responses of wild-type and mutant receptors to $1 \mathrm{mM}$ ACh were $2.9 \pm 0.2(N=4)$ and $1.7 \pm 0.13(N=4)$ times larger, respectively, than the $100 \mu \mathrm{M}$ ACh control responses in the same cells.

As noted above, measurements of agonist-induced residual inhibition were made based on changes in the response to control $100 \mu \mathrm{M}$ $\mathrm{ACh}$ applications. The values for the $\mathrm{C} 2 / \mathrm{C} 1$ ratios were plotted as functions of the experimental agonist concentrations applied between the $\mathrm{C} 2$ and $\mathrm{C} 1$ control responses. The data were then fit to the Hill equation with $n$ constrained to equal -1 for the calculation of $\mathrm{IC}_{50}$ values (Table 1). Determination of significant differences between experimental and control groups (Figs. 4-6) was made by unpaired two-tailed $t$ test.

For experiments assessing voltage dependence of inhibition, oocytes were voltage-clamped at the indicated holding potential for both control applications of ACh alone and test applications of experimental agonists and/or antagonists. After a 5-min wash period, cells were given another control ACh application at the indicated potential so that residual inhibition could be evaluated.

\section{Results}

$\beta$ Subunit TM2 Mutations Promote Agonist-Induced Residual Inhibition by ACh and Nicotine. As previously reported for receptors containing chimeric $\beta 4$ subunits (Webster et al., 1999), receptors containing the $\beta 46^{\prime}$ and $10^{\prime}$ point mutations showed decreased responses to repeated applications of $\mathrm{ACh}$ and nicotine, suggesting that these agonists produce some form of residual inhibition (Fig. 1). Although the inhibition produced by nicotine persisted for up to $1 \mathrm{~h}$ (not shown), inhibition produced by ACh was more reversible with essentially full recovery after 7 to 8 min of wash (Fig. 1C).

The concentration-response function for the activation of nicotine and the inhibition of wild-type and mutant receptors is shown in Fig. 2. The presence of the $6^{\prime}$ and $10^{\prime}$ mutations in the $\beta 4$ subunit appeared to increase the efficacy of nicotine compared with ACh and to substantially increase the ago-

TABLE 1

$\mathrm{IC}_{50}$ values

\begin{tabular}{ccccc}
\hline Drug & Receptor & Holding Potential & $\mathrm{IC}_{50}$ & Figure Reference \\
\hline \multirow{2}{*}{ Nicotine } & $\alpha 3 \beta 4$ & -50 & $\mu 1000$ & $2 \mathrm{~B}$ \\
& $\alpha 3 \beta 4\left(6^{\prime} \mathrm{F} 10^{\prime} \mathrm{T}\right)$ & -50 & $29 \pm 5$ & $2 \mathrm{~B}$ \\
DMXB & $\alpha 3 \beta 4$ & -50 & $121 \pm 48$ & $3 \mathrm{~B}$ \\
& $\alpha 3 \beta 4\left(6^{\prime} \mathrm{F} 10^{\prime} \mathrm{T}\right)$ & -50 & $23 \pm 17$ & $3 \mathrm{~B}$ \\
\hline
\end{tabular}

nist-induced residual inhibition measured after a 5-min wash. However, the interpretation of the efficacy data in Fig. $2 \mathrm{~A}$ is complicated by the fact that the measurement is based on a comparison with ACh-evoked currents. Noncompetitive inhibitory or desensitizing effects limit the apparent efficacy of nicotine in wild-type $\alpha 3$-containing receptors (Papke et al., 2000 ), and the effect of the $6^{\prime} / 10^{\prime}$ mutations seems to be primarily on the rate of recovery from nicotine-induced inhibition. It may be the case that the $6^{\prime} / 10^{\prime}$ mutations are having the effect of producing more agonist-induced residual inhibition during an ACh-evoked response. If this is the case, then much of the apparent increase in the relative efficacy of nicotine may be due to a decrease in the absolute efficacy of ACh.

TM2 Mutations Differentially Regulate the Activation and Inhibition of Subtype-Selective Agonists. As shown in Fig. 2, the $6^{\prime} / 10^{\prime}$ mutations appear to influence both activation and agonist-induced residual inhibition, raising the question of whether these effects are likely to represent multiple consequences of these agonists binding to a single site on the receptor (i.e., the activation binding site), or alternatively represent effects from binding to multiple sites on the receptors. To test this, the effects of other agonists on the wild-type and mutant receptors were investigated. Specifically, two subtype-selective agents were used that previously have been reported to be only weak partial agonists on wildtype $\alpha 3 \beta 4$ receptors, DMXB and TC-2403. DMXB is an $\alpha 7$ selective partial agonist (Meyer et al., 1997) that can produce agonist-induced residual inhibition of wild-type receptors in the absence of strong activation. As shown in Fig. 3, the $6^{\prime} / 10^{\prime} \beta 4$ mutations did not cause DMXB to appear as a more efficacious agonist (Fig. 3A) than for the wild-type receptor, but they did cause DMXB to produce more inhibition after it was applied at 100 or $300 \mu \mathrm{M}$ (Fig. 3B; $p<0.001$ ). In contrast, the greatest effect of the $6^{\prime} / 10^{\prime} \beta 4$ mutations on the activity of the $\alpha 4 \beta 2$-selective agonist TC-2403 was in measurement of apparent efficacy (Fig. 3C), since there was no significant increase in residual inhibition at concentrations less than $1 \mathrm{mM}$ (Fig. 3D). Even after the application of $1 \mathrm{mM}$ TC-2403, residual inhibition was minimal; responses were still $70 \pm 6 \%$ of the preapplication control values.

The Residual Inhibition Produced by Agonists is Voltage-Dependent. We evaluated the voltage dependence of the residual inhibition of wild-type $\alpha 3 \beta 4$ and $\alpha 3 \beta 4\left(6^{\prime} \mathrm{F} 10^{\prime} \mathrm{T}\right)$ receptors produced by DMXB, as well as the enhanced inhibition of $\alpha 3 \beta 4\left(6^{\prime} \mathrm{F} 10^{\prime} \mathrm{T}\right)$ mutant receptors by nicotine and ACh to see if the inhibition had properties that would be consistent with open-channel blockade. Cells were held at either -50 or -100 $\mathrm{mV}$ and tested for their response to control concentrations of ACh. After a 10-min wash, test agonists (ACh, DMXB, or nicotine) were applied at the concentrations indicated. Cells were then washed for $5 \mathrm{~min}$ and tested again for their response to a control ACh application. Cells were held at the indicated holding potential throughout the entire procedure. As shown in Fig. 4 , the residual inhibition of both wild-type and mutant receptors was enhanced if the cells were held at a hyperpolarized potential (Fig. 4). This would be consistent with inhibition associated with binding to a channel-associated site (e.g., openchannel block).

DMXB-Induced Inhibition of Mutant Receptors is Use-Dependent. As shown in Fig. 5, the inhibition of wildtype $\alpha 3 \beta 4$ receptors by DMXB is not enhanced when the 


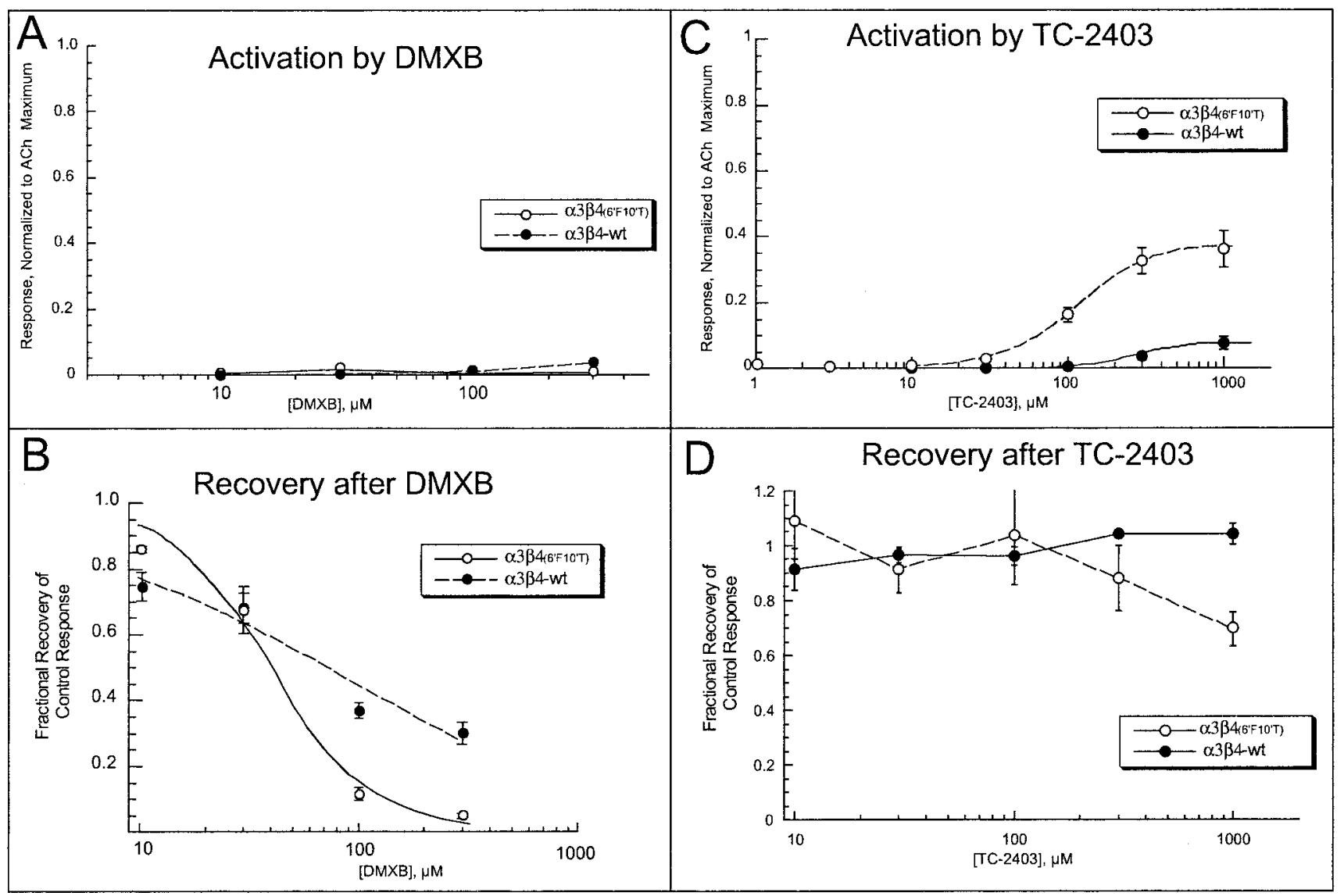

Fig. 3. Concentration-response curves for the effect of DMXB and TC-2403 on $\alpha 3 \beta 4$ and $\alpha 3 \beta 4\left(6^{\prime} \mathrm{F} 10^{\prime} \mathrm{T}\right)$ receptors. A, the concentration-response relationship for the activation of the peak currents by DMXB. Data are expressed relative to ACh maximum responses (see Materials and Methods). $\mathrm{B}$, the concentration-response relationship for the recovery of control ACh response amplitude measured 5 min after DMXB was applied at the indicated concentrations. C, the concentration-response relationship for the activation of the peak currents by TC-2403. Data are expressed relative to ACh maximum responses (see Materials and Methods). D, the concentration-response relationship for the recovery of control ACh response amplitude measured 5 min after TC-2403 was applied at the indicated concentrations. Each point represents the average normalized response of at least four cells.

weak partial agonist DMXB is coapplied with the full agonist ACh. Raw data obtained when $100 \mu \mathrm{M}$ ACh was applied alone or coapplied with $30 \mu \mathrm{M}$ DMXB is shown in panel A. Although $100 \mu \mathrm{M}$ DMXB produced greater inhibition than 30 $\mu \mathrm{M}$ DMXB (Fig. 5B), the amount of inhibition was unaffected by coapplication of ACh. This apparent lack of use dependence is in contrast with our previous observation that DMXB-induced inhibition of $\alpha 4 \beta 2$ receptors is enhanced when the drug is coapplied with ACh (de Fiebre et al., 1995). Interestingly, use dependence is apparently altered in the receptors containing the $\beta 4\left(6^{\prime} \mathrm{F} 10^{\prime} \mathrm{T}\right)$ subunit (Fig. 5), such that the coapplication of ACh with $30 \mu \mathrm{M}$ DMXB produced a large increase in the residual inhibition. As can be seen in the raw data (Fig. $5 \mathrm{C}$ ), the currents of the $\alpha 3 \beta 4\left(6^{\prime} \mathrm{F} 10^{\prime} \mathrm{T}\right)$ receptors in response to ACh and DMXB reach peak very rapidly, consistent with use-dependent inhibition. Note that both the wild-type and mutant receptors have similar $\mathrm{EC}_{50}$ values for activation by $\mathrm{ACh}$ (Table 2). Due to this similarity in $\mathrm{EC}_{50}$ values, the ability of the ACh stimulus to produce use-dependent effects should have been similar for channels.

Whereas the results presented in Fig. 5 suggest a clear difference in the inhibition of wild-type and mutant receptors by DMXB, interpretation of the data should also include consideration that as a weak partial agonist, DMXB effectively prevents ACh from being effective during the coappli- cations. That is, since DMXB is apparently capable of both competitive interactions with $\mathrm{ACh}$ at the activation site and a use-dependent binding to a channel-associated site, when ACh is coapplied with DMXB, ACh cannot promote the usedependent effects because DMXB is blocking activation. Specifically, the responses of both wild-type and mutant receptors to $100 \mu \mathrm{M}$ ACh were decreased a similar amount when the ACh was coapplied with $30 \mu \mathrm{M}$ DMXB. The responses of $\alpha 3 \beta 4$ receptors to the DMXB/ACh coapplication were only $12 \pm 1 \%$ the response to $\mathrm{ACh}$ alone and the responses of $\alpha 3 \beta 4\left(6^{\prime} \mathrm{F} 10^{\prime} \mathrm{T}\right)$ receptors were reduced to $13 \pm 2 \%$. When 100 $\mu \mathrm{M}$ DMXB was coapplied to wild-type receptors with $100 \mu \mathrm{M}$ $\mathrm{ACh}$, the activation was only $4 \pm 0.2 \%$ the activation produced by ACh alone. It may be the case that, for the wild-type receptors, DMXB may have a similar affinity for both activation and inhibitory sites so that competitive inhibition masks use-dependent effects. If in the mutant receptors there is increase only in affinity for the inhibitory site compared with wild-type, then use-dependent inhibition would become more apparent.

Protection of $\alpha 3 \beta 4\left(6^{\prime} \mathrm{F}^{\prime} 0^{\prime} \mathrm{T}\right)$ Receptors from Residual Inhibition Produced by Agonists. Since QX-314 and tetracaine both produce a readily reversible voltage-dependent inhibition of $\alpha 3 \beta 4$ receptors (Papke et al., 2001), it was determined whether by pretreating the receptors with a high 


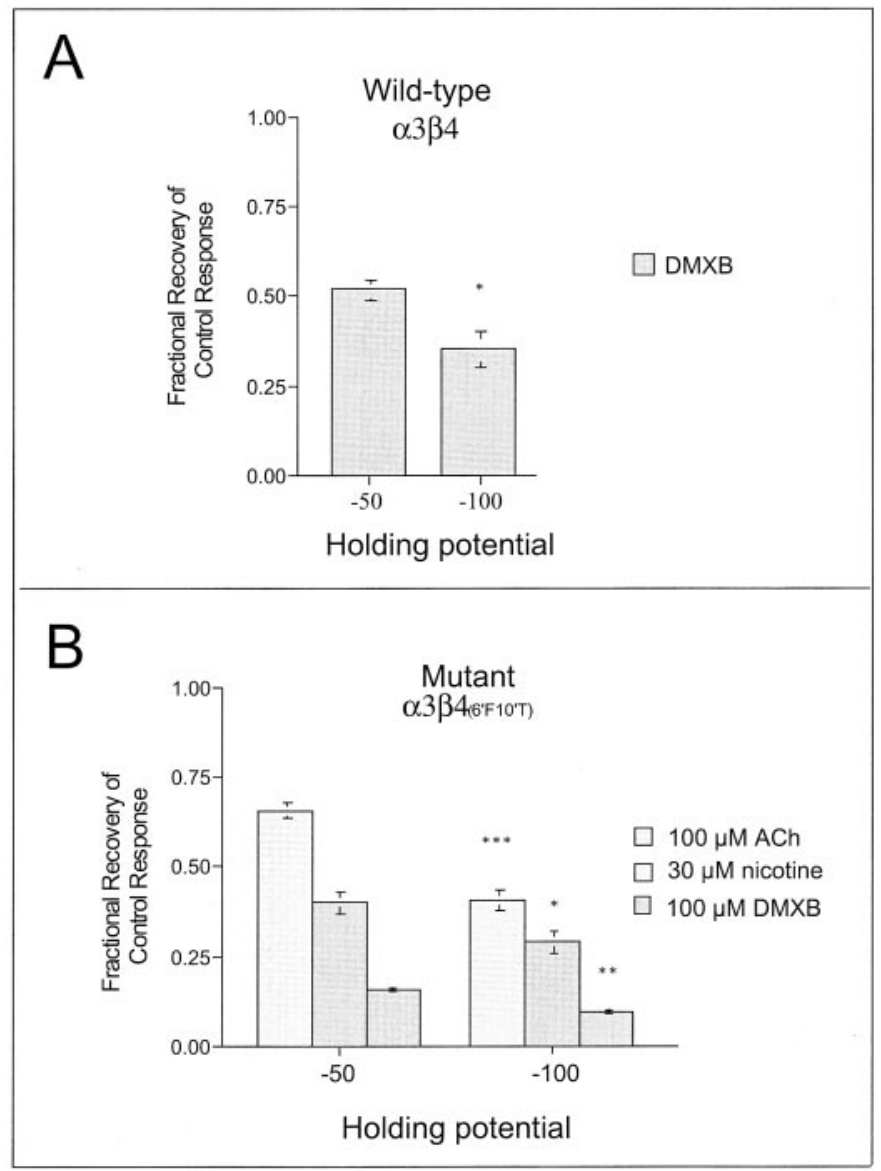

Fig. 4. The effect of hyperpolarization on the inhibition measured after the application of agonists. A, oocytes expressing wild-type $\alpha 3 \beta 4$ receptors were treated with $100 \mu \mathrm{M}$ DMXB at a holding potential of either -50 or $-100 \mathrm{mV}$. After a 5-min wash at the test potential, control applications of ACh were measured and expressed relative to initial control responses obtained at the same potential. B, oocytes expressing $\alpha 3 \beta 4\left(6^{\prime} \mathrm{F} 10^{\prime} \mathrm{T}\right)$ receptors were treated with the indicated agonists at a holding potential of either -50 or $-100 \mathrm{mV}$. After a 5 -min wash at the test potential, control applications of $\mathrm{ACh}$ were measured and expressed relative to initial control responses obtained at the same potential. For this experiment, the initial ACh control measurements were obtained $10 \mathrm{~min}$ before the experimental agonist application to minimize the residual inhibition produced by the first ACh control. *, $p<0.05$; **, $p<0.01 ; * * *, p<0.001$.

concentration of these agents so as to saturate their binding sites the function of the receptors could be protected from the relatively long-lived inhibition produced by the application of $100 \mu \mathrm{M}$ DMXB. As shown in Fig. 6A, neither of these agents provided any protection from the DMXB-induced inhibition. However, when cells were pretreated with TC-2403, there was a significant $(p<0.05)$ reduction in the residual inhibition produced by DMXB (Fig. 6A). Note that a concentration of $100 \mu \mathrm{M}$ TC-2403 was used since it was the $\mathrm{EC}_{50}$ for activation of the mutant receptors and was a concentration that did not produce any inhibitory effects on its own. Tetracaine, QX-314, and TC-2403 were then evaluated for their ability to protect $\alpha 3 \beta 4\left(6^{\prime} \mathrm{F} 10^{\prime} \mathrm{T}\right)$ receptors from the residual inhibition produced by either $100 \mu \mathrm{M}$ DMXB or $300 \mu \mathrm{M}$ nicotine. As shown in Fig. 6B, significant protection of receptor function was provided by TC-2403 $(p<0.01$ for DMXB inhibition and $p<0.05$ for nicotine inhibition) but not by local anesthetics.

\section{Discussion}

The mutations characterized in the $\beta$ subunit TM2 were first identified because they determined the sensitivity of neuronal receptor subtypes to selective noncompetitive inhibitors classified as ganglionic blockers based on their preferential inhibition of receptors containing neuronal-type $\beta$ subunits (i.e., $\beta 2$ or $\beta 4$ ). It was noted that in addition to having a reduced sensitivity to the classic ganglionic blocker mecamylamine, compared with wild-type, receptors with the $\beta 4\left(6^{\prime} \mathrm{F} 10^{\prime} \mathrm{T}\right)$ subunit showed increased residual inhibition after exposure to nicotine (Webster et al., 1999). In the present paper, to determine to what extent the effects of these mutations might be generalized to other agonists, the analysis of $\alpha 3 \beta 4\left(6^{\prime} \mathrm{F} 10^{\prime} \mathrm{T}\right)$ receptors was expanded to look at the effects of these mutations on the activity of the two selective agonists DMXB and TC-2403. Competition experiments were conducted to determine whether the increased agonist-induced residual inhibition observed was most consistent with enhanced desensitization, channel block by an agonist (steric inhibition), or alternatively some form of allosteric inhibition.

A strict classical definition of desensitization requires that the inhibition follows from binding to the very same sites where the agonists bind to promote channel activation. On the other hand, channel block or "steric" inhibition would be distinguished as the binding of the agonist molecules to a site (or sites) within the conduction pathway, such that the presence of the agonist prevents current flow. In the case of allosteric inhibition, the agonists would be assumed to be binding to a class of sites that selectively stabilized the closed or desensitized states without directly blocking the channel.

The results obtained with the two selective agonists DMXB and TC-2403 suggest that the effects of the $6^{\prime} / 10^{\prime}$ mutations on apparent efficacy and inhibition may not be interdependent since DMXB manifested only increased inhibition and TC-2403 manifested primarily an increase in relative efficacy. One possibility might be that the mutations are affecting the coupling efficiency between agonist binding and channel gating for some agonists (i.e., nicotine and TC-2403) but at the same time improving a binding site within the channel for a steric inhibition (i.e., open-channel block) by other agonists (i.e., all but TC-2403). Alternatively, the mutations may simply promote more rapid desensitization (although, again TC-2403 would be the exception).

However, defining desensitization as an inactivation process promoted by the binding (or retention of) agonist at the activation binding site, it would seem unlikely that the inactivation of $\alpha 3 \beta 4\left(6^{\prime} \mathrm{F} 10^{\prime} \mathrm{T}\right)$ receptors by $\mathrm{DMXB}$ would represent desensitization since it is promoted by the binding of $\mathrm{ACh}$ to the activation site. This apparent use dependence would also suggest that DMXB, nicotine, and ACh may have their enhanced inhibitory effects by binding to sites within the ion channel such as those associated with open-channel block. Such a mechanism would also be consistent with the observed voltage dependence for inhibition of both the wildtype and mutant receptors.

The local anesthetic QX-314 has been characterized as an open-channel blocker of various nicotinic AChR subtypes (Neher and Steinbach, 1978; Horn et al., 1980; Francis et al., 1998; Pascual and Karlin, 1998; Wilson and Karlin, 2001). Tetracaine has been shown to have both competitive and 


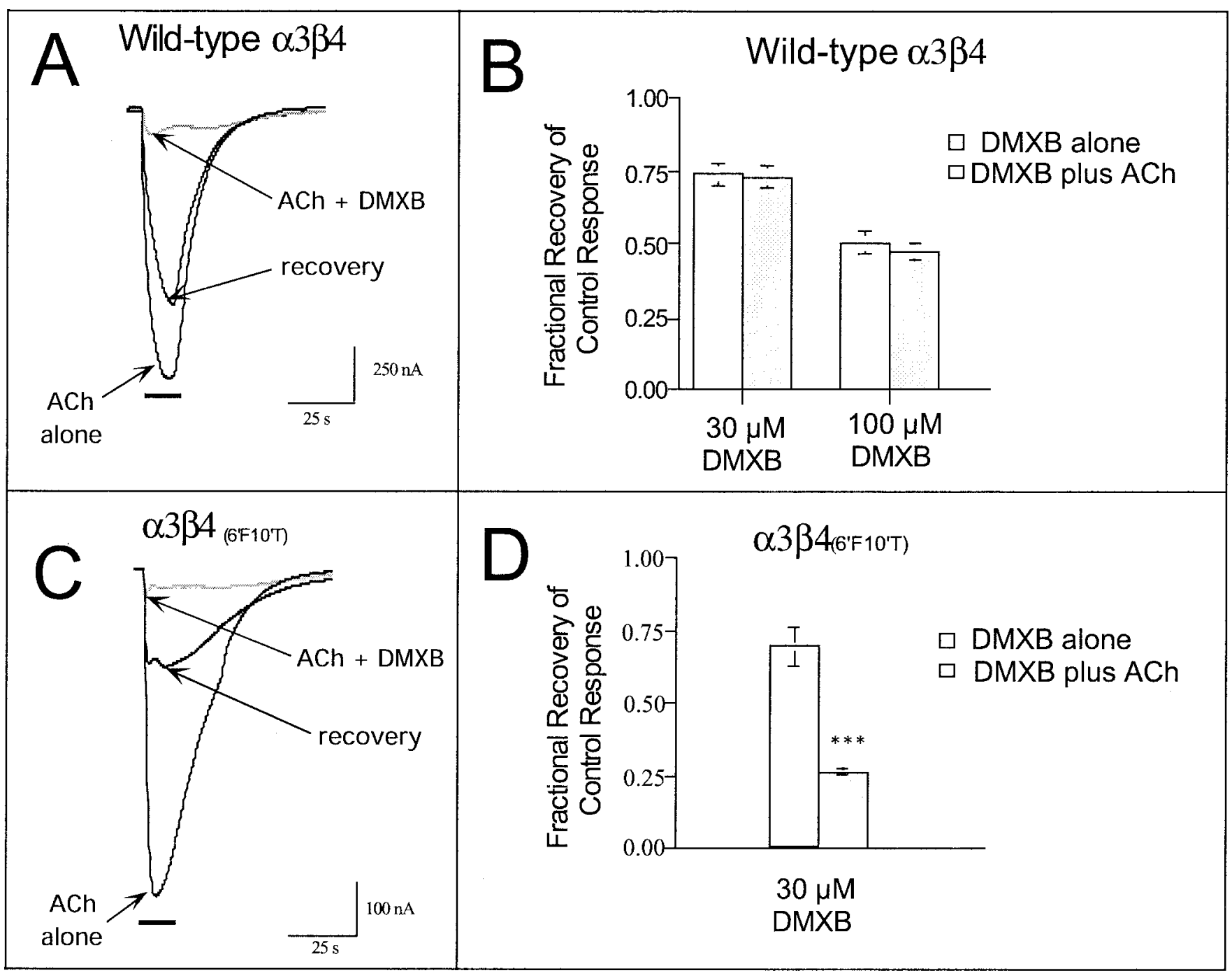

Fig. 5. Use dependence of inhibition by DMXB. A, raw data obtained from an oocyte expressing wild-type $\alpha 3 \beta 4$ receptors. The cell was first stimulated with $100 \mu \mathrm{M}$ ACh alone (left arrow) and then with $30 \mu \mathrm{M}$ DMXB in combination with $100 \mu \mathrm{M}$ ACh (thick gray trace). After a 5-min wash, the cell was retested with $100 \mu \mathrm{M}$ ACh (recovery, right arrow). B, data obtained from oocytes expressing wild-type $\alpha 3 \beta 4$ receptors treated with 30 or $100 \mu \mathrm{M}$ DMXB alone or in combination with $100 \mu \mathrm{M}$ ACh. After a 5-min wash, the cells were then reevaluated for their response to control applications of $100 \mu \mathrm{M}$ $\mathrm{ACh}$. The data plotted represent average residual ACh control responses of at least four oocytes. C, raw data obtained from an oocyte expressing wild-type $\alpha 3 \beta 4\left(6^{\prime} \mathrm{F} 10^{\prime} \mathrm{T}\right)$ receptors. The cell was first stimulated with $100 \mu \mathrm{M}$ ACh alone (left arrow) and then with $30 \mu \mathrm{M}$ DMXB in combination with $100 \mu \mathrm{M}$ ACh (thick gray trace). After a 5-min wash, the cell was retested with $100 \mu \mathrm{M}$ ACh (recovery, right arrow). D, data obtained from oocytes expressing $\alpha 3 \beta 4\left(6^{\prime} \mathrm{F} 10^{\prime} \mathrm{T}\right)$ receptors treated with $30 \mu \mathrm{M}$ DMXB alone or in combination with $100 \mu \mathrm{M}$ ACh. After a 5-min wash, the cells were then reevaluated for their response to control applications of $100 \mu \mathrm{M}$ ACh. The data plotted represent average residual ACh control responses of at least four oocytes.

TABLE 2

Curve fits for Hill equations

\begin{tabular}{|c|c|c|c|c|c|}
\hline Agonist & Receptor & Max Response* & $n$ & $\mathrm{EC}_{50}$ & Figure Reference \\
\hline & & & & $\mu M$ & \\
\hline Nicotine & $\begin{array}{c}\alpha 3 \beta 4 \\
\alpha 3 \beta 4\left(6^{\prime} \mathrm{F} 10^{\prime} \mathrm{T}\right)\end{array}$ & $\begin{array}{l}0.88 \pm 0.04 \\
0.20 \pm 0.05\end{array}$ & $\begin{array}{l}1.2 \pm 0.2 \\
0.8 \pm 0.3\end{array}$ & $\begin{array}{l}96 \pm 16 \\
30 \pm 18\end{array}$ & $\begin{array}{l}2 \mathrm{~A} \\
2 \mathrm{~B}\end{array}$ \\
\hline $\mathrm{ACh}^{\dagger}$ & $\begin{array}{c}\alpha 3 \beta 4 \\
\alpha 3 \beta 4\left(6^{\prime} \mathrm{F} 10^{\prime} \mathrm{T}\right)\end{array}$ & $\begin{array}{l}1.0 \\
1.0\end{array}$ & $\begin{array}{l}2.1 \pm 0.6 \\
0.8 \pm 0.1\end{array}$ & $\begin{array}{l}68 \pm 12 \\
72 \pm 17\end{array}$ & \\
\hline
\end{tabular}

* Relative to ACh maximum

Data taken from Papke et al., 2001.

noncompetitive effects on nicotinic AChR function. When functioning as a noncompetitive antagonist, tetracaine appears to have comparable affinity for receptors in the resting and open states (Papke and Oswald, 1989; Takayama et al.,
1989; Gallagher and Cohen, 1999; Middleton et al., 1999; Blanton et al., 2000). Therefore, these two agents should serve as effective probes for channel-associated sites and in fact may distinguish between sites associated with different 


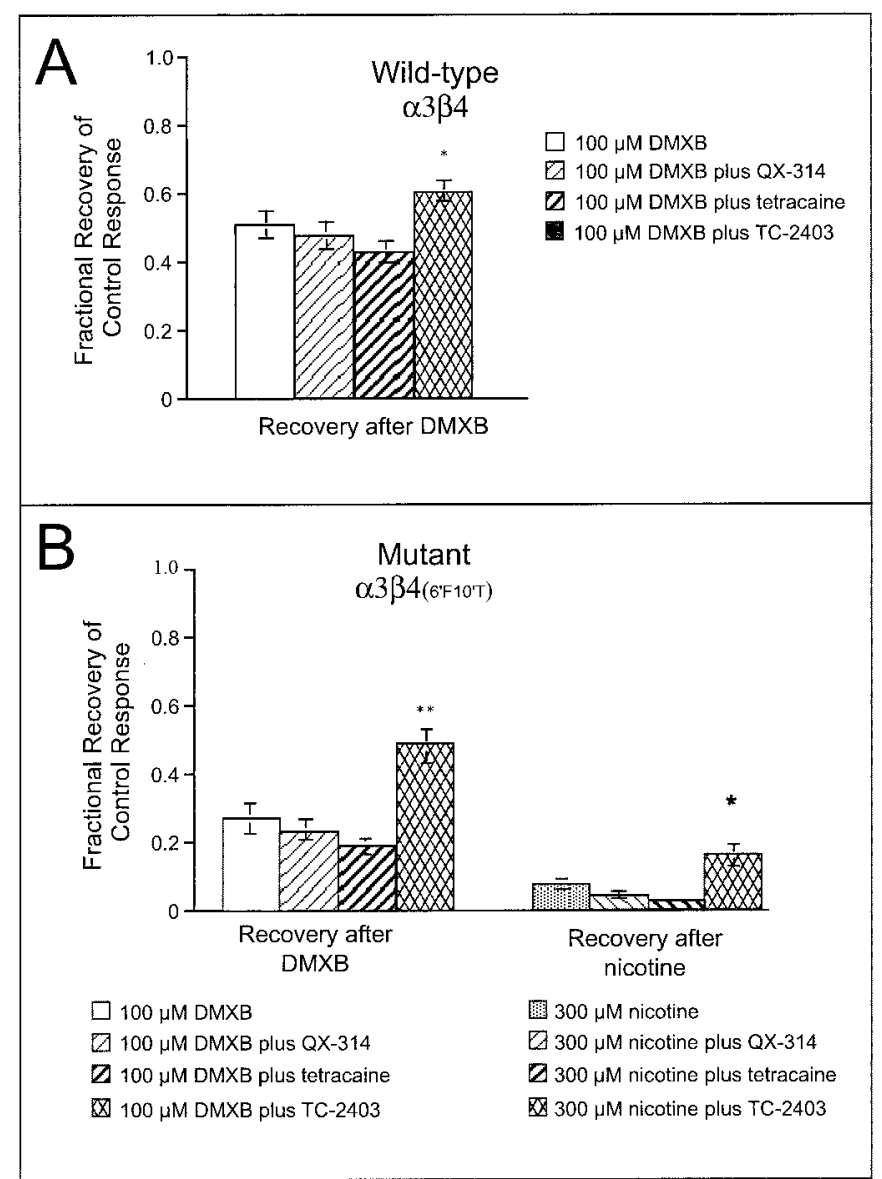

Fig. 6. Protection of receptor function. A, oocytes expressing wild-type $\alpha 3 \beta 4$ receptors were treated with $100 \mu \mathrm{M}$ DMXB alone or in the presence of $20 \mu \mathrm{M}$ QX-314, $100 \mu \mathrm{M}$ tetracaine, or TC-2403. Control $100 \mu \mathrm{M} \mathrm{ACh}$ responses were then measured after a 5-min wash and compared with the initial ACh control responses. Only the coapplication of $100 \mu \mathrm{M}$ TC-2403 was effective at decreasing the residual inhibition measured after the application of $100 \mu \mathrm{M}$ DMXB. B, the bars on the right illustrate the results obtained when oocytes expressing $\alpha 3 \beta 4\left(6^{\prime} \mathrm{F} 10^{\prime} \mathrm{T}\right)$ receptors were treated with $100 \mu \mathrm{M}$ DMXB alone or in coapplication with $200 \mu \mathrm{M}$ QX-314, $100 \mu \mathrm{M}$ tetracaine, or $100 \mu \mathrm{M}$ TC-2403. Control $100 \mu \mathrm{M}$ ACh responses were measured after a 5-min wash and compared with the initial ACh control responses. Only the coapplication of $100 \mu \mathrm{M}$ TC-2403 was effective at decreasing the residual inhibition measured after the application of $100 \mu \mathrm{M}$ DMXB. The bars on the left illustrate the results obtained when oocytes expressing $\alpha 3 \beta 4\left(6^{\prime} \mathrm{F} 10^{\prime} \mathrm{T}\right)$ receptors were treated with $300 \mu \mathrm{M}$ nicotine alone or in coapplication with $200 \mu \mathrm{M}$ QX-314, 300 $\mu \mathrm{M}$ tetracaine, or $100 \mu \mathrm{M}$ TC-2403. Note that nicotine is an efficacious agonist for the mutant receptor, and we have shown that the inhibitory effects of tetracaine on the mutant receptor are decreased with high levels of agonist activation (Papke et al., 2001). Therefore, we chose to use a somewhat higher concentration of tetracaine in this nicotine protection experiment. Control $100 \mu \mathrm{M}$ ACh responses were measured after a 5-min wash and compared with the initial $\mathrm{ACh}$ control responses. Only the coapplication of $100 \mu \mathrm{M}$ TC-2403 was effective at decreasing the residual inhibition measured after the application of $300 \mu \mathrm{M}$ nicotine. Note that for both panels A and B, cells were pre-equilibrated for $12 \mathrm{~s}$ with QX-314, tetracaine, or TC-2403 before coapplication of DMXB or nicotine with the indicated agents.

forms of channel blockade. The fact that the residual inhibition produced by DMXB and nicotine was unperturbed by the binding of either QX-314 or tetracaine would argue against the idea that these agonists produce that inhibition by binding to the same channel-associated site recognized by the local anesthetics.

Furthermore, the observation that protection from inhibition was provided by a drug that lacks intrinsic inhibitory activity suggests that the binding site protected by TC-2403 is unlikely to be a site within the conduction pathway (i.e., an open-channel block site), or TC-2403 itself would have had inhibitory effects. An alternative interpretation therefore is that the agonists are working at a proposed allosteric regulatory site (Rozental et al., 1989; Min and Weiland, 1992; Yost and Dodson, 1993; Arias, 1996), the accessibility of which is regulated by gating.

Since TC-2403 can protect receptor function from the longterm inhibition caused by other agonists, TC-2403 may bind to an allosteric site also recognized by other agonists but not promote the inhibition of function through that binding. As shown in Fig. 3, TC-2403 is an effective activator of $\alpha 3 \beta 4$ $\left(6^{\prime} \mathrm{F} 10^{\prime} \mathrm{T}\right)$ receptors, but unlike ACh, TC-2403 acts to prevent rather than promote DMXB-induced inhibition. This would indicate that the protective effects of TC-2403 are not associated with its binding to the activation sites (where it behaves like ACh) but rather to different sites where the other agonists promote inhibition but where TC-2403 does not. This would be most consistent with an allosteric binding site, since as noted above, it seems unlikely that TC-2403 would bind to a site within the conduction pathway and not inhibit function. However, since the effects of the inhibitory agonists (i.e., ACh, DMXB, and nicotine) do appear to be voltage-dependent, if they are associated with binding to an allosteric site, then it may be the case that the conformation or accessibility of such a site is influenced by gating and/or membrane voltage.

TC-2403 provided a relatively modest amount of protection to wild-type $\alpha 3 \beta 4$ receptors compared with the effects on the mutant subtype, which shows enhanced inhibition by an agonist. However, wild-type receptors naturally differ in the degree to which they show residual inhibition by nicotine and other agonists (Papke et al., 2000), and the effects of nicotine on $\alpha 3 \beta 4$ receptors is small compared with its effects on $\alpha 4 \beta 2$ receptors. Therefore, the fact that TC-2403 can protect nicotinic receptors from the inhibitory aftereffects of other agonists may ultimately have important clinical significance. Nicotine and other potentially therapeutic agents (Papke et al., 1997) have very mixed profiles of agonist and antagonist activity. Since TC-2403 can protect wild-type receptors from DMXB-induced inhibition, it may be the case that this agent will be able to protect other receptor subtypes (e.g., $\alpha 4 \beta 2$ ) from long-term inhibitory effects of nicotine and other agonists with inhibitory side effects. In this way then, coadministration of TC-2403 with other agents may provide a way to tune a spectrum of effects in such a way as to enhance a subtype-selective activation. This might be most applicable to the clinical development of an $\alpha 7$-selective agent like DMXB (GTS-21).

In conclusion, it appears that specific sequence in the TM2 can regulate both the sensitivity of specific nicotinic receptor subtypes to channel-blocking agents and effects at sites outside of the ion channel conduction pathway, presumably by affecting gating-dependent conformational changes in the receptor. This effect of $\beta$ subunit TM2 sequence on gatingdependent conformational changes is consistent with our previous report on the regulation of voltage-independent usedependent inhibition by bis(2,2,6,6-tetramethyl-4-piperidyl)sebacate (Tinuvin 770) (Francis et al., 1998). Although the $6^{\prime} / 10^{\prime}$ mutation decreases the inhibitory effects of bis $(2,2,6,6$ tetramethyl-4-piperidyl)sebacate at sites outside the ion channel, these mutations increase inhibition by selected agonists 
and shift the affinity of tetracaine away from a channelassociated site and toward the activation binding site (Papke et al., 2001). The ability of TC-2403 to protect receptor function from allosteric inhibition produced by other agonists may point toward valuable new combination drug therapies.

\section{Acknowledgments}

I thank Dr. Steve Heinemann and Jim Boulter for providing nicotinic AChR cDNAs. The mutant $\beta 4$ subunits were constructed and cloned by Clare Stokes. I also thank Julia Porter, Chad Wheeler, and Jennifer Cruse for technical assistance and Drs. Patrick M. Lippiello, Merouane Bencherif, Stephen Baker, Edwin Meyer, and Robert Oswald for helpful discussions.

\section{References}

Arias HR (1996) Agonist self-inhibitory binding site of the nicotinic acetylcholine receptor. J Neurosci Res 44:97-105.

Blanton MP, McCardy EA, and Gallagher MJ (2000) Examining the noncompetitive antagonist-binding site in the ion channel of the nicotinic acetylcholine receptor in the resting state. $J$ Biol Chem 275:3469-3478.

de Fiebre CM, Meyer EM, Zoltewicz J, Henry JC, Muraskin S, Kem WR, and Papke RL (1995) Characterization of a family of anabaseine-derived compounds reveals that the 3-(4)-dimethylaminocinnamylidine derivative (DMAC) is a selective agonist at neuronal nicotinic $\alpha 7 /\left[{ }^{125} \mathrm{I}\right] \alpha$-bungarotoxin receptor subtypes. Mol Pharmacol 47:164-171.

Francis MM, Choi KI, Horenstein BA, and Papke RL (1998) Sensitivity to voltageindependent inhibition determined by pore-lining region of ACh receptor. Biophys $J$ 74:2306-2317.

Gallagher MJ and Cohen JB (1999) Identification of amino acids of the torpedo nicotinic acetylcholine receptor contributing to the binding site for the noncompetitive antagonist $[(3) \mathrm{H}]$ tetracaine. Mol Pharmacol 56:300-307.

Galzi JL, Revah F, Bouet F, Menez A, Goeldner M, Hirth C, and Changeux JP (1991) Allosteric transitions of the acetylcholine receptor probed at the amino acid level with a photolabile cholinergic ligand. Proc Natl Acad Sci USA 88:5051-5055.

Heinemann S, Boulter J, Connolly J, Goldman D, Evans K, Treco D, Ballivet M, and Patrick J (1986) Molecular biology of the muscle and neural acetylcholine receptors, in Nicotinic Acetylcholine Receptor Structure and Function (Maelicke A ed) NATO ASI series vol H3, pp 359-387, Springer-Verlag, Berlin.

Horn R, Brodwick MS, and Dickey WD (1980) Asymmetry of the acetylcholine channel revealed by quaternary anesthetics. Science (Wash DC) 210:205-207.

Katz B and Thesleff S (1957) A study of the "desensitization" produced by acetylcholine at the motor end-plate. $J$ Physiol (Lond) 138:63-80.

Meyer E, Kuryatov A, Gerzanich V, Lindstrom J, and Papke RL (1998) Analysis of $40 \mathrm{H}-\mathrm{GTS}-21$ selectivity and activity at human and rat $\alpha 7$ nicotinic receptors. $J$ Pharmacol Exp Ther 287:918-925.
Meyer EM, Tay ET, Papke RL, Meyers C, Huang G, and de Fiebre CM (1997) Effects of 3-[2,4-dimethoxybenzylidene] anabaseine (DMXB) on rat nicotinic receptors and memory-related behaviors. Brain Res 768:49-56.

Middleton RE, Strnad NP, and Cohen JB (1999) Photoaffinity labeling the torpedo nicotinic acetylcholine receptor with $[(3) \mathrm{H}]$ tetracaine, a nondesensitizing noncompetitive antagonist. Mol Pharmacol 56:290-299.

Miller C (1988) Genetic manipulation of ion channels: a new approach to structure and mechanism. Neuron 2:1195-1205.

Min CK and Weiland GA (1992) Substance P inhibits carbamylcholine-stimulated $22 \mathrm{Na}^{+}$efflux from acetylcholine receptor-enriched Torpedo electroplaque membrane vesicles. Brain Res 586:348-351.

Neher E and Steinbach JH (1978) Local anaesthetics transiently block current through single acetylcholine receptor channels. J Physiol (Lond) 277:135-176.

Papke RL, Horenstein BA, and Placzek AN (2001) Inhibition of wild-type and mutant neuronal nicotinic acetylcholine receptors by local anesthetics. Mol Pharmacol 60:1-10.

Papke RL and Oswald RE (1989) Mechanisms of noncompetitive inhibition of acetylcholine-induced single channel currents. J Gen Physiol 93:785-811.

Papke RL, Thinschmidt JS, Moulton BA, Meyer EM, and Poirier A (1997) Activation and inhibition of rat neuronal nicotinic receptors by ABT-418. $\mathrm{Br} J$ Pharmacol 120:429-438.

Papke RL, Webster JC, Lippiello PM, Bencherif M, and Francis MM (2000) The activation and inhibition of human nAChR by RJR-2403 indicate a selectivity for the $\alpha 4 \beta 2$ receptor subtype. $J$ Neurochem 75:204-216.

Pascual JM and Karlin A (1998) Delimiting the binding site for quaternary ammonium lidocaine derivatives in the acetylcholine receptor channel. J Gen Physiol 112:611-621.

Rozental R, Scoble GT, Albuquerque EX, Idriss M, Sherby S, Sattelle DB, Nakanishi K, Konno K, Eldefrawi AT, and Eldefrawi ME (1989) Allosteric inhibition of nicotinic acetylcholine receptors of vertebrates and insects by philanthotoxin. $J$ Pharmacol Exp Ther 249:123-130.

Takayama H, Majewska MD, and London ED (1989) Interactions of noncompetitive inhibitors with nicotinic receptors in the rat brain. J Pharmacol Exp Ther 251: 1083-1089.

Webster JC, Francis MM, Porter JK, Robinson G, Stokes C, Horenstein B, and Papke RL (1999) Antagonist activities of mecamylamine and nicotine show reciprocal dependence on beta subunit sequence in the second transmembrane domain. $\mathrm{Br} J$ Pharmacol 127:1337-1348.

Wilson G and Karlin A (2001) Acetylcholine receptor channel structure in the resting, open, and desensitized states probed with the substituted-cysteineaccessibility method. Proc Natl Acad Sci USA 98:1241-1248.

Yost CS and Dodson BA (1993) Inhibition of the nicotinic acetylcholine receptor by barbiturates and by procaine: do they act at different sites? Cell Mol Neurobiol 13:159-172.

Address correspondence to: Dr. Roger L. Papke, Department of Pharmacology and Therapeutics, Box 100267 JHMHSC, University of Florida, Gainesville, FL 32610-0267. E-mail: rpapke@college.med.ufl.edu 